\title{
Pathological Diversity in Clinical Syndromes of Pituitary Hypersecretion: Its Significance in Evaluating their Surgical Treatment
}

\author{
Harley S. Smyth
}

\begin{abstract}
Thorough pathological examination disclosed considerable diversity of abnormal cell types and correspondingly different surgical correction rates among patients with apparently similar syndromes of pituitary hypersecretion. The surgical correction of acromegaly in patients with densely granulated growth hormone tumours was threefold that in patients whose tumours showed sparse granulation. Two non-prolactinoma tumour types associated with hyperprolactinemia have aggressive growth patterns; their special therapeutic management is discussed. Of 33 patients with Cushing's disease solitary adenomas were found in only 14 , while six patients had proven corticotroph cell hyperplasia. Elective hypophysectomy should replace selective adenomectomy in selected cases of Cushing's disease.
\end{abstract}

RÉSUMÉ: La diversité pathologique dans les syndromes cliniques d'hypersécrétion hypophysaire: son importance dans l'évaluation du traitement chirurgical L'examen pathologique complet chez des patients qui présentaient des syndromes d'hypersécrétion hypophysaire semblables a montré une grande diversité dans le type de cellules anormales observées et donc dans le résultat des opérations correctrices. Dans l'acromégalie, le taux de succès était trois fois plus élevé pour les tumeurs à hormone de croissance dont les granulations étaient denses que pour celles à granulations éparses. Deux tumeurs de type non-prolactinome, mais associées à une hyperprolactinémie, semblent présenter une croissance agressive. Nous en discutons le traitement spécial. Chez 33 patients avec maladie de Cushing nous avons trouvé des adénomes solitaires chez seulement 14 sujets; 6 autres avaient une hyperplasie des cellules corticotrophes prouvée. L’hypophysectomie élective devrait remplacer l'adénectomie sélective chez certains cas de maladie de Cushing.

Can. J. Neurol. Sci. 1985: 12:358-362

Hypersecretory pituitary syndromes fall into three main clinical categories. Table 1 illustrates the relative incidence of pituitary syndromes or pituitary cell types encountered at operation for intrasellar tumour in a recent analysis of our series at the Wellesley Hospital, which now numbers over 300 cases. As in most reported general series of comparable size, ${ }^{1}$ the three main hypersecretory syndromes involving growth hormone (GH), prolactin (PRL) and adrenocorticotropic hormone (ACTH) account for two-thirds (67.8\%) of the cases. Respectively, 71 showed clinical signs of acromegaly (with giantism in two cases); 89 presented with amenorrhea and/or galactorrhea (or male impotency) and infertility; 32 had Cushing's disease. The cases within each of these three sub-populations were ostensibly uniform in their clinical and biochemical manifestations. However, detailed pathological analysis of the surgical specimens has revealed that these groups are not in fact homogeneous popula- tions when studied from an immunocytochemical or electron microscopic viewpoint.

\section{Growth Hormone Hypersecretion: Acromegaly}

It is now clear that apparently similar cases of acromegaly may result from any one of at least 5 histological tumour types that are distinctly recognizable by immunocytochemical and electron microscopic (EM) studies. Table 2 outlines the relative incidence of cell types and their combinations in 64 acromegalic patients whose histological study in this manner was complete.

Mammosomatotroph tumours The relatively rare mammosomatotroph tumour is a monomorphous tumour whose cells elaborate and release both growth hormone and prolactin, although growth hormone secretion greatly predominates. There is a male preponderence of its incidence. Earlier described as a primarily morphologic entity without specific clinical features, 


\section{Table 1: Intrasellar Tumours}

\begin{tabular}{lrc}
\hline \hline & No. & $\%$ \\
Acromegaly, Giantism & 71 & 25.1 \\
Prolactinoma & 89 & 31.4 \\
Cushing's Disease & 32 & 11.3 \\
Nelson's Syndrome & 4 & 1.4 \\
Acidophile Stem Cell & 4 & 1.4 \\
Gonadotroph & 4 & 1.4 \\
Silent Corticotroph & 10 & 3.5 \\
Null Cell, Oncocytoma & 26 & 9.2 \\
Unclassified & 19 & 6.7 \\
Craniopharyngioma & 12 & 4.2 \\
Arachnoid Cyst & 7 & 2.5 \\
Mucocoele & 1 & 0.4 \\
Secondary Carcinoma & 4 & 1.4 \\
& 283 & 99.9 \\
\hline
\end{tabular}

\begin{tabular}{lrc}
\hline Table 2: Growth Hormone Tumours & & \\
\hline \hline Acromegaly & 18 & $\%$ \\
Densely Granulated HGH Cell Adenoma & 16 & 25 \\
Sparsely Granulated HGH Cell Adenoma & 8 & 12.5 \\
Mammosomatotroph Adenoma & 7 & 10.9 \\
Polyhormonal Adenoma & 14 & 21.9 \\
Mixed Adenoma HGH + PRL & & \\
Giantism & $\frac{1}{1.6}$ & $\frac{100}{\text { Mammosomatotroph Adenoma }}$ \\
& 64 & 100 \\
\hline
\end{tabular}

its occurrence appears to indicate the formation of a tumour cell line from an early stem cell in the "eosinophilic" series. ${ }^{2}$

Growth Hormone Cell Adenomas The majority (53.1\%) of GH secreting adenomas are of two cell types, the densely granulated (DG) and sparsely granulated (SG) GH cell adenomas. (See Fig. 1(a) and (b)) In another study ${ }^{3}$ of 46 patients treated for acromegaly by selective trans-spenoidal removal of $\mathrm{GH}$ secreting adenomas, we were interested in correlating the efficacy of surgical treatment with a number of factors, including tumour stage, preoperative blood levels of $\mathrm{GH}$, previous treatment, and histologic cell type. Our clinical population was typical of that of several similar surgical series of comparable size. ${ }^{4.5}$ There was a $2: 1$ ratio of males to females, and an average age of presentation of 43.6 years. The duration of signs and symptoms ranged from 6 months to 30 years, with an average of 9 years, indicating a typical delay in diagnosis and treatment in keeping, perhaps, with a persistent tendency to regard acromegaly as a benign chronic illness.

Biochemical correction rates correlated typically both with tumour stage and size (see table 3 ) and also to a predictable degree with preoperative growth hormone levels (fig. 2). The rate of biochemical correction was a competitive $93 \%$ for stage 1 and stage 2 enclosed tumours. ${ }^{6}$

Of particular interest however, was the correlation of preand post-operative GH levels with tumour cell type in 34 patients whose pathological specimens were sufficient to allow their complete characterization by EM and immunostaining methods. Table 4 displays three findings. Neither SG nor DG GH cell adenomas showed a greater tendency to produce excessively high blood levels of GH. GH levels above and below $40 \mu \mathrm{g} / \mathrm{L}$. were evenly distributed between SG and DG tumour cell types responsible. Despite this, the rate of correction was $94.4 \%$ for DG GH adenomas compared to only $56.3 \%$ for SG GH cell tumours. Otherwise stated, DG GH cell adenomas accounted for nearly three-quarters of all cases corrected. This finding is open to interpretation, but it may signify important quantitative differences in granule formation and release by the two cell types. To date, we have found no correlation between cell granulation type and clinical symptoms, tumour size, recurrence rate, or anomalous responsiveness of $\mathrm{GH}$ to thyroid releasing hormone, though these are factors that are still under study.

Mixed Adenomas Mixed adenomas are bimorphous tumours with two distinct cell types, each containing either GH or prolactin. Their incidence in this series was $21.9 \%$. The relatively high success rate (9/11) of their biochemical correction in this series may be a reflection of their histological pattern; they are almost without exception constituted by DG GH adenoma cells and SG PRL adenoma cells. Fig. 3 illustrates the correction of both GH and PRL hypersecretion in 4 such patients.

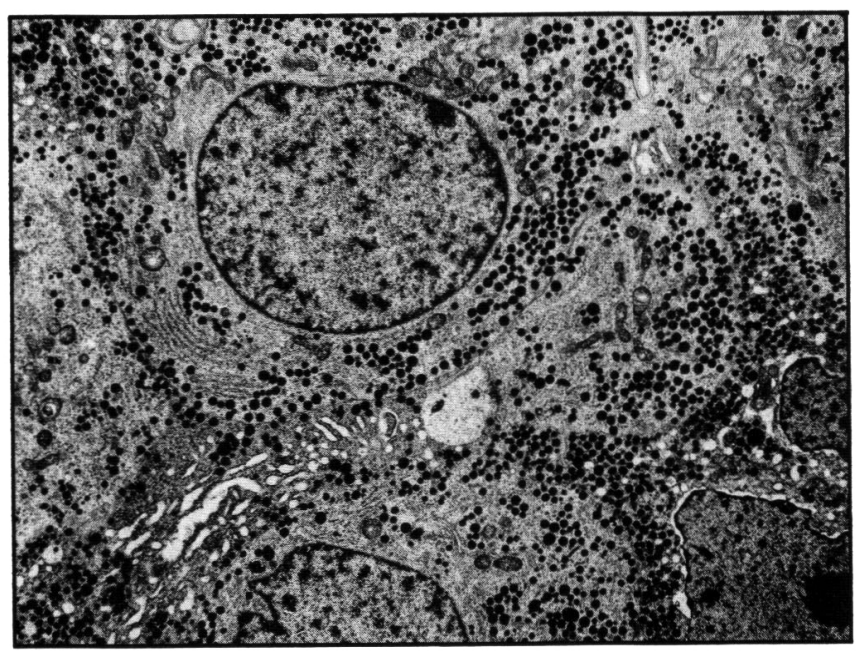

Figure I(a) - Densely gradulated GH cell adenoma. Electron micrograph (Mag. $11,200 X)$

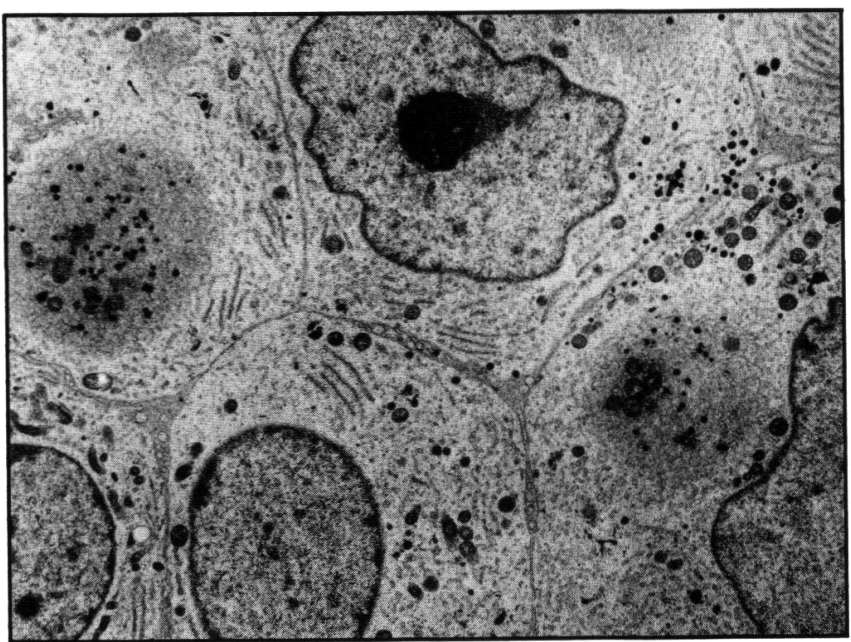

(b) - Sparsely granulated GH cell adenoma. Electron micrograph (Mag. 13,150 X)

Courtesy of Dr. E. Horvath and Dr. K. Kovacs, St. Michael's Hospital. Toronto 


\begin{tabular}{|c|c|c|c|c|c|}
\hline \multirow[t]{6}{*}{ Stage } & I & & No. Pts. & $\begin{array}{c}\text { Corrected } \\
4\end{array}$ & $\begin{array}{r}\% \\
100\end{array}$ \\
\hline & II & $\begin{array}{l}\mathrm{O} \\
\mathrm{A} \\
\mathrm{B}\end{array}$ & $\begin{array}{r}14 \\
6 \\
3 \\
\end{array}$ & $\begin{array}{r}12 \\
6 \\
3 \\
\end{array}$ & $\begin{array}{r}85.7 \\
100 \\
100 \\
\end{array}$ \\
\hline & & & 27 & 25 & 92.6 \\
\hline & III & $\begin{array}{l}\text { O } \\
\text { A } \\
\text { B }\end{array}$ & $\begin{array}{r}10 \\
2 \\
4\end{array}$ & $\begin{array}{l}5 \\
0 \\
1\end{array}$ & $\begin{array}{r}50 \\
0 \\
25\end{array}$ \\
\hline & IV & $\begin{array}{l}\mathrm{O} \\
\mathrm{A} \\
\mathrm{C}\end{array}$ & $\begin{array}{l}1 \\
\frac{1}{46}\end{array}$ & $\begin{array}{r}0 \\
1 \\
0 \\
32\end{array}$ & $\begin{array}{r}0 \\
50 \\
0 \\
36.8\end{array}$ \\
\hline & & & & Overall & $69.6 \%$ \\
\hline
\end{tabular}

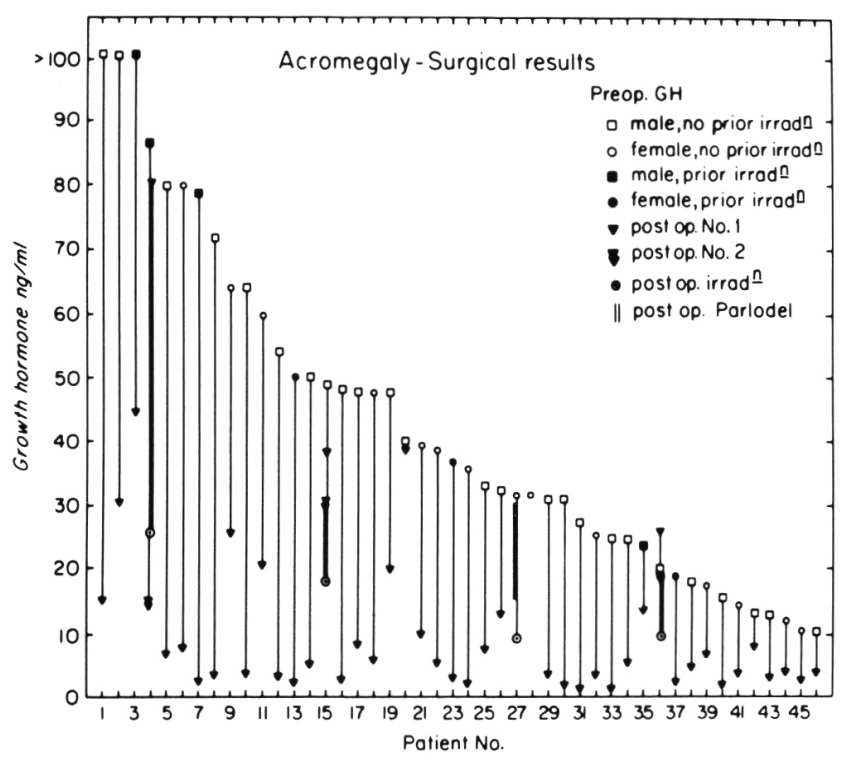

Figure 2 - Acromegaly: response to treatment - survey of 46 cases

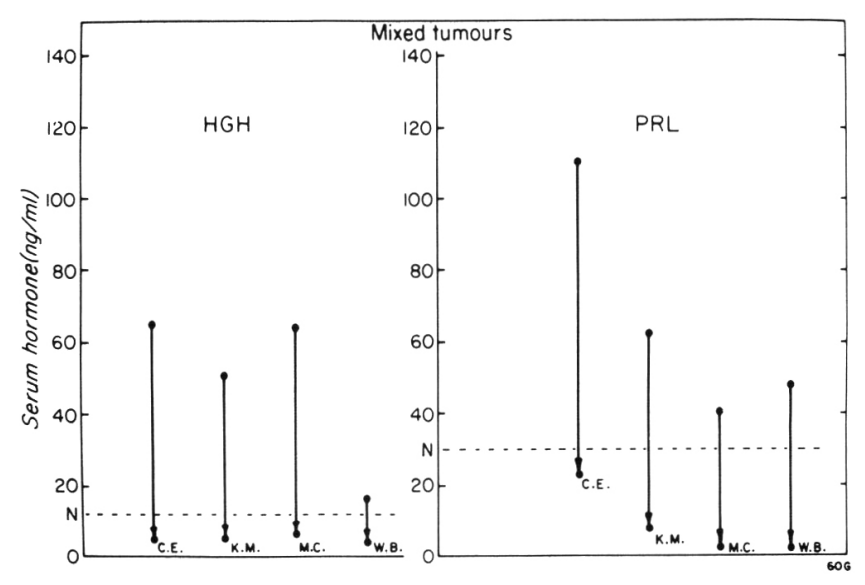

Figure 3 - Correction of both HGH and PRL levels in 4 patients with mixed adenomas.

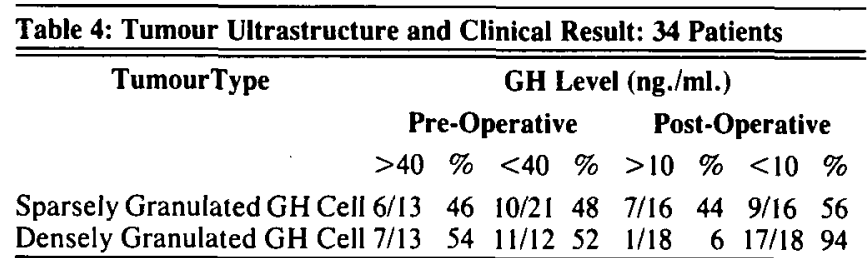

\section{Hyperprolactinemia}

A diversity of pathology was also found in patients with hyperprolactinemia. PRL is elevated non-specifically in a wide variety of physiological states, including sleep, exercise, stress, pregnancy and early lactation. Abnormal elevation of PRL may result from ingestion of phenothiazines, tricyclic antidepressants, beta-blockers, cimetidine and metoclopramide. When sustained hyperprolactinemia is associated with clinical or radiographic evidence of an intrasellar tumour, the differential diagnosis must include a variety of pituitary fossa lesions as well as prolactinoma. Table 5 illustrates the final histologic diagnosis in our first 60 cases of intrasellar tumour with hyperprolactinemia. Only 46 patients ( $76.6 \%$ ) harboured true prolactinomas as confirmed by $\mathrm{EM}$ and immunocytochemical study.

Prolactin may be elevated in the presence of non-secreting tumours whose suprasellar extension interrupts the normal influence of the hypothalamic prolactin inhibiting factor - the so-called "stalk section" effect. Two other tumour cell types require specific mention.

Acidophile Stem Cell Adenomas The histologically immature and clinically aggressive acidophile stem cell adenoma is responsible for a clinicopathologic entity characterized by a short clinical history, local (particularly inferior) invasiveness, and relatively modest hyperprolactinemia. Although $\mathrm{GH}$ is also demonstrable in small amounts in a majority of these tumours, acromegalic features are rare, and females predominate. ${ }^{8}$ In view of the invasive nature of their tumours, 3 of our 4 cases have received postoperative radiation, and it is now our policy to recommend this for all such patients, even the very young.

Silent Corticotroph Adenomas The surgical correction of high preoperative levels of PRL may enhance the likelihood of misdiagnosis of prolactinoma. The attendant hazards of this error and the importance of a prompt, accurate electronmicroscopic diagnosis are best illustrated by the following case report:

A 28 year old woman suffered rapid bilateral visual loss. Demyelinating disease was suspected, but visual field examination revealed severe bitemporal hemianopia with early macular involvement. Sellar tomography revealed thinning and destruction of the sellar floor by a soft tissue mass filling the posterior third of the sphenoid sinus. Preoperative investigation was cut short when her visual loss progressed swiftly to legal blindness. She was admitted for an emergency operation. A single blood sample taken after anaesthetic induction showed undetectable levels of LH and FSH, and a PRL of $70.2 \mu \mathrm{g} / \mathrm{L}$. (normal range 5-25) Trans-sphenoidal removal of a friable, hemorrhagic tumour led to prompt and complete recovery of visual fields and acuity. As her postoperative PRL levels remained normal, no further treatment was offered at follow-up. Five months later she became pregnant. Within a month she again reported reduced vision in the left eye and a recurrent bitemporal hemianopia progressed rapidly. At this time, an EM diagnosis of the tumour removed 6 months earlier was returned as "silent corticotrophic adenoma." At the second operation, a large recurrent tumour was selectively removed with careful preservation of normal gland. Postoperative radiation was administered during the second trimester of pregnancy; she remained well, and was delivered at full term of a healthy boy. 
Table 5: Tumours with Hyperprolactinaemia

\section{Prolactinoma}

Mixed Adenoma (GH,PRL)

Non-secreting

Acidophile Stem Cell Adenoma

Unclassified

Polyhormonal (MEA I)

Intrasellar Arachnoid Cyst
46

5

3

2

2

1

$\frac{1}{60}$
The falsely reassuring normal postoperative PRL levels in this case led to the mistaken diagnosis of prolactinoma and delayed treatment appropriate for this patient's charcteristically aggressive silent corticotroph tumour - treatment which could have prevented its recurrence. The diagnosis of prolactinoma can be confirmed only by immunohistology and electron microscopy, and this confirmation should be obtained promptly after operation.

Silent corticotroph (SC) tumours are a distinct pathological entity ${ }^{9}$, but certain clinical features may induce a high index of suspicion for pre-operative diagnosis. They show a marked tendency to rapid growth, haemorrhagic infarction, and fulminant optic compromise. Three of 14 previously published cases, and 7 of our 14 current surgical cases showed hyperprolactinemia. SC adenomas are basophilic and PAS positive, and although unassociated with hypercorticism, contain variable amounts of ACTH, $\beta$-lipotropin, and $\alpha$-endorphin. Their association with hyperprolactinemia may result from a "stalk-section" effect, or alternatively, endorphin may stimulate the increased release of PRL from normal surrounding lactotroph cells.

Though SC tumours accounted for $43 \%$ of tumours of corticotrophic origin in the pathological series ${ }^{9}$, there are only 10 of 46 in our surgical series. Those of the greatest interest are associated with Cushing's disease.

\section{Cushing's Disease}

It is uncommonly appreciated that in the classic 1932 description of the disease that now bears his name, Harvey Cushing was able to locate adenomas in only 7 of the original 12 cases collected. ${ }^{10}$ While this ratio sufficed to establish his thesis, it is intriguing to speculate that his chosen subtitle, "Pituitary Basophilism," may have been left as a caveat for a wider interpretation. He described for us what would one day pose a singular surgical problem; these tumours might be of exceedingly small diameter (under $3 \mathrm{~mm}$.), they might hide laterally in a recess, and they had a proclivity to burrow posteriorly into the neurohypophysis. The search for, and selective removal of these lesions remains a challenging technical problem, but current reports of extensive experience imply a high degree of early success when such a tumour is found and removed. "It has become the accepted view that the great majority, if not all cases of Cushing's disease are caused by discrete, clearly demarcated adenomas. ${ }^{12} \mathrm{I}$ will describe the measure in which our experience has differed from this account in the following brief survey of our findings in Cushing's disease, some of which have been reported earlier. ${ }^{13}$

Thirty-three patients ( 28 females and 5 males) ranging in age from 14 to 60 years, presented with clinical features of Cushing's syndrome. All demonstrated hypercorticism as indicated by 24-hour measurements of urinary free cortisol, and its pituitary- dependency was inferred from low and high dose Dexamethasone suppression tests in all cases. In radiological studies the pituitary fossa was normal in 24 patients, showed subtle lateralized abnormalities in 6, and was enlarged in only 3. CT scanning demonstrated focal abnormality in 12 patients, but was normal in 15. The subsequent trans-sphenoidal operation was thus exploratory in a majority of the cases. Operation was abandoned in 2 patients because of profuse perisellar venous bleeding, and no pituitary biopsy was obtained. Of the remaining 31 patients, a discrete pituitary adenoma was the sole pathological finding in only 14. A 15 th patient whose adenoma had been treated previously with proton beam therapy, was also found to harbour nests of corticotroph cells in the peritumourous gland at a subsequent second operation for hypophysectomy. Adenomatous cell nests were the only finding in 2 other patients. In 2 patients, Crooke's cell change was the only detectable abnormality. In I patient with a notably enlarged sella, diffuse homogeneous enlargement of the gland was the only finding. Five cases showed no pathological change in tissue resected because of suspected focal abnormality.

In two other patients with similar focal nodules, uniform hyperplastic change with a normal reticulin pattern was found with no evidence of tumour formation. Four pituitary glands, 3 of which were totally removed at elective complete anterior hypophysectomy, displayed diffuse multifocal corticotroph cell hyperplasia, interspersed with normal adenohypophysis (see figure 4).

The selective removal of solitary adenomas led to sustained remission of hypercorticism in 13 of 14 cases. This result was also achieved in 4 of the 6 patients with hyperplasia, but at the expense of complete hypophysectomy, planned preoperatively. Median wedge resection resulted in complete remission in 1 patient, but serial sectioning of this tissue revealed a $1 \mathrm{~mm}$. adenoma (see Table 6).

While a few early reports ${ }^{14}$ refer to findings suggestive of hyperplasia, most recent papers are lacking in evidence for a detailed pathological search for this finding using modern techniques. While we accept that hyperplasia is likely to account

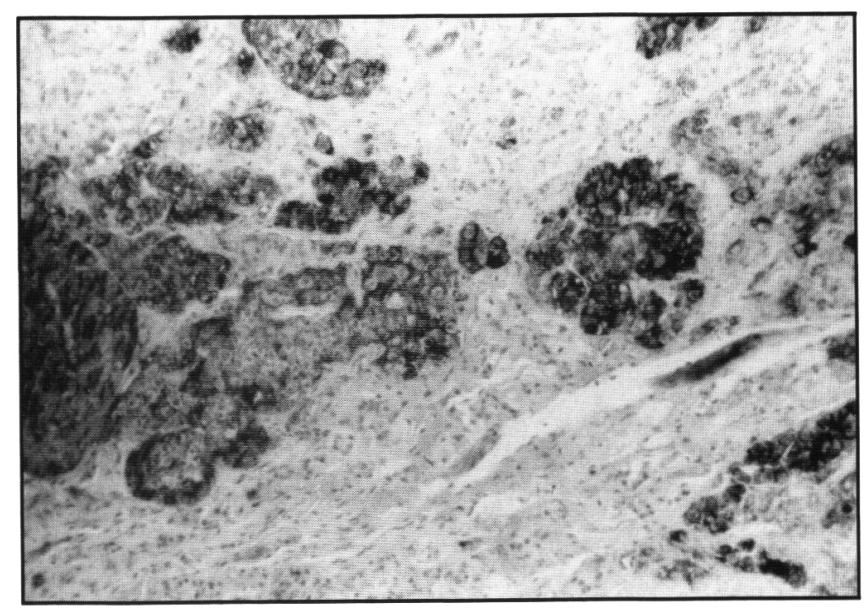

Figure 4 - Diffuse multifocal corticotroph cell hyperplasia in Cushing' sdisease. Immunoperoxidase technique shows ACTH.positivity in multiple. separate acini.

Immunocytochemical staining and photomicrograph courtesy of Dr. Kovacs, St. Michael's Hospital, Toronto 
for a minority of cases of Cushing's disease, we believe it to be more prevalent than previously suspected. The awareness of this possibility should lead, we believe, to the preoperative consideration of complete hypophysectomy in the event that no tumour is found after systematic trans-sphenoidal exploration.

Table 6: Cushing's Disease: Correlation of Pathological Findings and Clinical Results

\begin{tabular}{lrcc}
\hline \hline Pathological Findings & No. & Remission & $\%$ \\
Solitary Adenoma & 14 & 13 & 92.9 \\
Adenoma + Cell Nests & 1 & 0 & 0 \\
Cell Nests Only & 2 & 0 & 0 \\
Crooke's Hyaline Change & 2 & 0 & 0 \\
Diffuse Enlargement & 1 & 0 & 0 \\
No Pathologic Diagnosis & 5 & 1 & 20 \\
Hyperplasia & & & \\
$\quad$ Focal Nodular & 2 & $\underline{3}$ (hypophx) & $\frac{75}{58.1}$ \\
Multifocal Diffuse & $\underline{4}$ & $\mathbf{1 8}$ & 50 \\
& $\mathbf{3 1}$ & & \\
\hline
\end{tabular}

\section{CONCLUSION}

The three main clinical categories of hypersecretory pituitary syndromes present as ostensibly uniform clinical populations. Each of them, however, is made up of distinguishable subtypes, each with a characteristic biology. In some instances, preoperative differentiation may be made by the recognition of an identifiable pattern of clinical and biochemical features, with important prognostic implications. In the special case of Cushing's disease, the search continues for a means of recognizing the important subgroup of cases who do not harbour tumours, but rather one or other variety of hyperplasia. Preoperative consideration of this diagnosis may dictate surgical policy. Until a reliable biochemical means of identification of these patients is found, elective total hypophysectomy should replace adenomectomy in certain selected cases of Cushing's disease, and in most if not all patients after childbearing age.

\section{ACKNOWLEDGEMENT}

The author wishes to acknowledge his profound debt to Drs. Kalman Kovacs and Eva Horvath for their close cooperation, encouragement and teaching, which has helped establish clinico-pathologic correlations and has led to the recognition of new sub-classifications within the main groups of patients with and without hypersecretory syndromes.

\section{REFERENCES}

I. Wilson CB, Dempsey LC. Transsphenoidal microsurgical removal of 250 pituitary adenomas. J Neurosurg 1978; 48:13-22.

2. Horvath E, Kovacs K, Killinger DW, Smyth HS, Weiss MH, Ezrin C. Mammosomatotroph cell adenoma of the human pituitary: a morphologic entity. Virchows Arch (Pathol Anat) 1983: 398:277-289.

3. Smyth HS, Wong M, Killinger DW. Results of transsphenoidal microsurgery for acromegaly: correlation of radiologic, biochemical and ultrastructural features in 46 cases. Can J Neurol Sci 1982; 9, 265, (Abstr).

4. Laws ER, Piepgras DG, Randall RV, Abboud CF. Neurosurgical management of acromegaly. Results in 82 patients treated between 1972 and 1977. J Neurosurg 1979; 50:454-461.

5. Giovanelli MA, Motti E, Paracchi A. Treatment of acromegaly by transsphenoidal microsurgery. J Neurosurg 1976; 44:677-686.

6. Hardy J, Somma M, Vezina JL. Treatment of acromegaly : radiation or surgery? In: Morley TP, ed. "Current Controversies in Neurosurgery." Saunders, Philadelphia. 1976; pp. 377-391.

7. Tolis G. Prolactin: Physiology and pathology. Hosp Pract 1980; 15:85-95.

8. Horvath E, Kovacs K, Singer W. Smyth HS, Killinger DW, Ezrin $\mathrm{C}$, Weiss $\mathrm{MH}$. Acidophile stem cell adenoma of the human pituitary: clinicopathological analysis of 15 cases. Cancer 1981; 47:761-771.

9. Horvath E, Kovacs K, Killinger DW, Smyth HS, Platts ME, and Singer $W$. Silent corticotropic adenomas of the human pituitary gland. A histologic, immunocytologic and ultrastructural study. Am J Pathol 1980; 98:617-638.

10. Cushing $H$. The basophil adenomas of the pituitary body and their clinical manifestations (pituitary basophilism). Bull John Hopkins Hosp 1932; 50:137-195.

11. Hardy J. Cushing's disease: 50 years later. Can J Neurol Sci 1982; 9:375-380.

12. Boggan JE, Tyrrell JB, Wilson CB. Transsphenoidal microsurgical management of Cushing's disease. Report of 100 cases. J Neurosurg 1983; 59:195-200.

13. Smyth HS, Horvath E, Kovacs K, Killinger DW. "Pituitary Basophilism": microsurgical observations on the pathogenesis of Cushing's disease. Ann Roy Coll Phys Surg Canada 1984; 17, 309. (Abstr).

14. Lüdecke D, Kautzky R, Saeger W, Schrader D. Selective removal of hypersecreting pituitary adenomas? An analysis of endocrine function, operative and microscopical findings in $10 \mathrm{l}$ cases. Acta Neurochir 1976; 35:27-42. 